\title{
ASSESSMENT OF RUSSIAN P/M SUPERALLOY EP741NP
}

\author{
John Radavich* and David Furrer** \\ *Micro-Met Laboratories, 209 North Street, West Lafayette, IN 47906, USA \\ **Ladish Co., Inc., PO Box 8902, Cudahy, WI 53110, USA
}

Keywords: As-HIP, HIP, Powder Metallurgy, Heat Treatment, Disc, Creep, Tensile

\begin{abstract}
$\underline{\text { Abstract }}$
An investigation was undertaken to assess the Russian P/M superalloy EP741NP. This alloy has been reported to be one of the most advanced Russian nickel-base superalloys used in AL31FP turbine engines for the current Sukoi fighters and other applications. $[1,2,3]$
\end{abstract}

Extensive metallographic investigations were undertaken on a sample of this alloy. Material was characterized in the as-received condition and after various thermal cycles. The microstructures and phases observed were not consistent with those expected or reported by others. Detailed metallographic characterization revealed the presence of large gamma-prime grain size and extensive prior particle boundaries (PPB's). These microstructural features appear to significantly impact the primary mechanical properties investigated for this as-HIP and heat treated superalloy disc material.

Mechanical property testing was performed to assess the mechanical property capabilities for this alloy. The results of this investigation have shown that this alloy has limited tensile strength capabilities, but may exhibit enhanced creep strength. The measured mechanical property values were compared with various literature values for this and other $\mathrm{P} / \mathrm{M}$ alloys.

\section{Experimental Procedure}

A sample of EP741NP was obtained from the Chinese Iron and Steel Research Institute (CISRI). The small, approximate $60 \mathrm{~mm}$ diameter by $35 \mathrm{~mm}$ tall sample was wire EDM'd from a production military turbine engine disc. This material was produced from $+50-150$ micron powder that was HIP consolidated into the disc configuration at $1200^{\circ} \mathrm{C} / 150 \mathrm{MPa} / 2 \mathrm{hrs}$. The gammaprime solvus for this alloy is between $1180^{\circ} \mathrm{C}$ and $1190^{\circ} \mathrm{C}$. [4] The resultant disc was solution heat treated at $1210^{\circ} \mathrm{C} / 8 \mathrm{hrs}$ followed by furnace cooling to $1160^{\circ} \mathrm{C}$ and then air cooling to room temperature. Aging was performed at $871^{\circ} \mathrm{C} / 32 \mathrm{hrs} / \mathrm{AC}$. [5]

The chemistry of the program material was tested to compare with literature reported values. Table I lists the measured chemistry for this alloy along with the typical aim chemistry values for EP741NP and several other nickel-base superalloys.

Table I. Chemistry of the EP741NP material studied in weight percent (Ni-remainder).

\begin{tabular}{|c|c|c|c|c|c|c|c|c|c|c|c|}
\hline & Cr & Co & Ti & Al & Mo & W & Zr & C & B & Nb & Other \\
\hline $\begin{array}{c}\text { EP741NP } \\
\text { Sample }\end{array}$ & 8.2 & 15.8 & 1.45 & 5.02 & 3.9 & 5.3 & $<0.01$ & 0.04 & $<0.015$ & 2.56 & $0.24 \mathrm{Hf}$ \\
\hline $\begin{array}{c}\text { Typical } \\
\text { EP741NP }\end{array}$ & 9.0 & 15.8 & 1.8 & 5.1 & 3.9 & 5.5 & $<0.015$ & 0.04 & $<0.015$ & 2.6 & $0.25 \mathrm{Hf}$ \\
\hline AF115 & 10.7 & 15 & 3.9 & 3.8 & 2.8 & 5.9 & 0.05 & 0.05 & 0.02 & 1.7 & $0.75 \mathrm{Hf}$ \\
\hline $\begin{array}{c}\text { AF2- } \\
\text { 1DA6 }\end{array}$ & 12 & 10 & 2.8 & 4.6 & 2.75 & 6.5 & 0.1 & 0.04 & 0.015 & -- & $1.5 \mathrm{Ta}$ \\
\hline U720LI & 16 & 15 & 5.0 & 2.5 & 3.0 & -- & 0.03 & 0.025 & 0.018 & -- & -- \\
\hline
\end{tabular}

The assessment of the EP741NP alloy was broken into three separate phases; 1) laboratory heat treatment of the EP741NP sample 2) metallographic characterization and $3)$ mechanical property testing.

\section{Laboratory Heat Treatments}

A section of the EP741NP was left in the as-received solution and age condition. One section of this material was heat treated to $2210 \mathrm{~F} / 8 \mathrm{hrs}$ followed by air cooling to room temperature and aged at $871^{\circ} \mathrm{C} / 32 \mathrm{hrs} / \mathrm{AC}$ (Heat Treatment-1). Another section of the material was re-heat treated with the same heat treatment reportedly given to the original material (Heat Treatment-2). A third section of this material was heat treated to $1210^{\circ} \mathrm{C} / 8 \mathrm{hrs}$ followed by furnace cooling to room temperature and aging at $871^{\circ} \mathrm{C} / 32 \mathrm{hrs} / \mathrm{AC}$ (Heat Treatment-3). A final section of 
this material was heat treated to $1210^{\circ} \mathrm{C} / 8 \mathrm{hrs}$ followed by furnace cooling to $968^{\circ} \mathrm{C}$, followed by air cooling to room temperature, and then aging at $871^{\circ} \mathrm{C} / 32 \mathrm{hrs} / \mathrm{AC}$ (Heat Treatment-6). Material from these five conditions, asreceived, Heat Treatment-1, Heat Treatment-2, Heat Treat-3 and Heat Treatment- 6 were used for the metallographic and structural analysis. Figure 1 shows schematically the heat treatments that were performed on the EP741NP material.

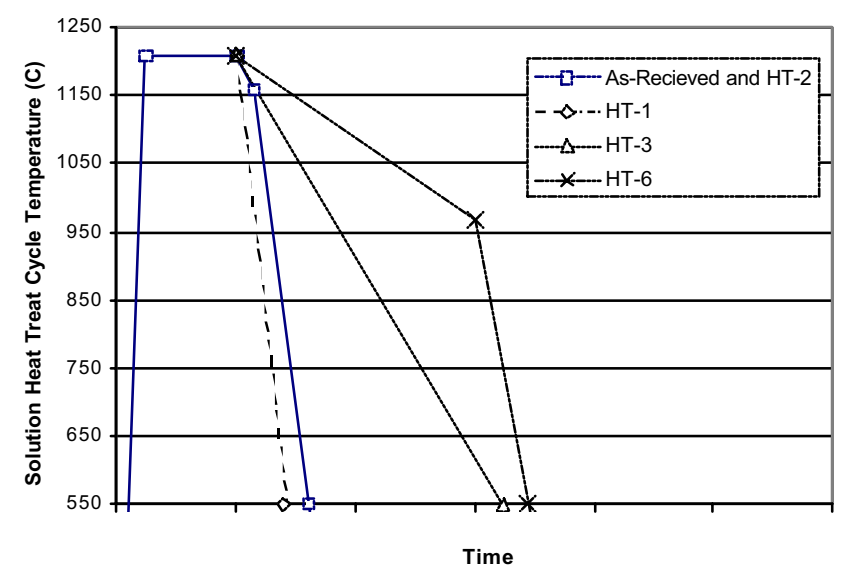

Figure 1. Schematic solution heat treatment cycles used to evaluate EP741NP material.

\section{Microstructural Characterization}

Light optical and SEM analyses were performed. For optical metallography, the samples were polished and swab etched with Kalling's reagent for grain size assessment. For SEM studies, two metallographic preparations were used. The first preparation method started with electropolishing with $20 \%$ sulfuric-methanol. This was followed by electrolytic etching in a $\mathrm{CrO}_{3}$ $\mathrm{H}_{3} \mathrm{PO}_{4}$-Sulfuric acid solution, which etched out any $\mathrm{Cr}$ carbides and put the gamma-prime phase in relief. In the second preparation, the samples were electropolished in a $10 \% \mathrm{HCl}-$ methanol solution, which put the inert carbides, borides, carbo-nitrides, etc, in greater relief and minimized gamma-prime relief. [6]

For X-ray phase identification, the samples were electrolytically extracted in a $10 \% \mathrm{HCl}-$ Methanol solution modified with tartaric acid. Without the tartaric acid, initial extractions resulted in the formation of a tungsten oxide. A small amount of the extracted residue was also evaluated in the SEM and probed for chemical composition.

\section{Mechanical Property Testing}

Wire EDM was used to section the sample piece into several mechanical property test specimen blanks. Two 0.125 " diameter tensile and two 0.125 " diameter creep specimens were machined from the as-received material.

Tensile testing was performed per ASTM E-8 requirements. Elevated temperature tensile tests were conducted to assess the static strength of this material.

Creep-rupture testing was performed at three creep conditions: $\quad 649^{\circ} \mathrm{C} / 690 \mathrm{MPa}, \quad 704^{\circ} \mathrm{C} / 690 \mathrm{MPa}$, and $871^{\circ} \mathrm{C} / 207 \mathrm{MPa}$ per ASTM E-139. The low temperature condition resulted in no creep after an extended period of time, so this sample was re-tested at the intermediate temperature condition.

\section{Results}

\section{Microstructural Characterization}

The as-received material exhibited extensive prior particle boundaries (PPB's). Figure 2 shows PPB's in the metallographic sample of the as-received material, while Figure 3 shows PPB's on the surface of a laboratory tensile fracture. The presence of the PPB's would be expected in an as-HIP and heat treated powder metallurgy superalloy material.

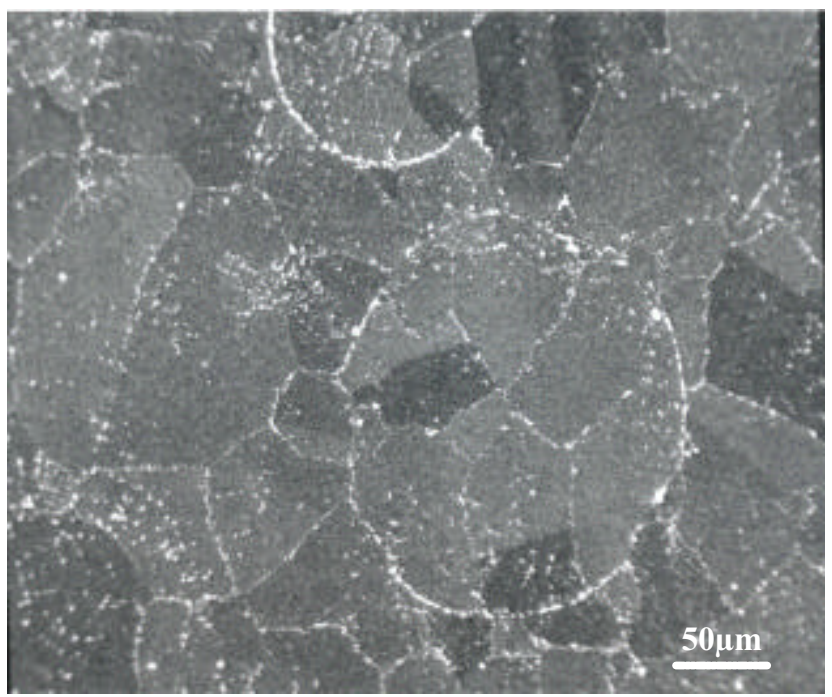

Figure 2. PPB microstructure of the as-received EP741NP.

The grain size for the as-received material was also reviewed and found to be very large. The grain size was ASTM average 6. Figure 4 shows a typical photomicrograph of the grain structure for this material. 


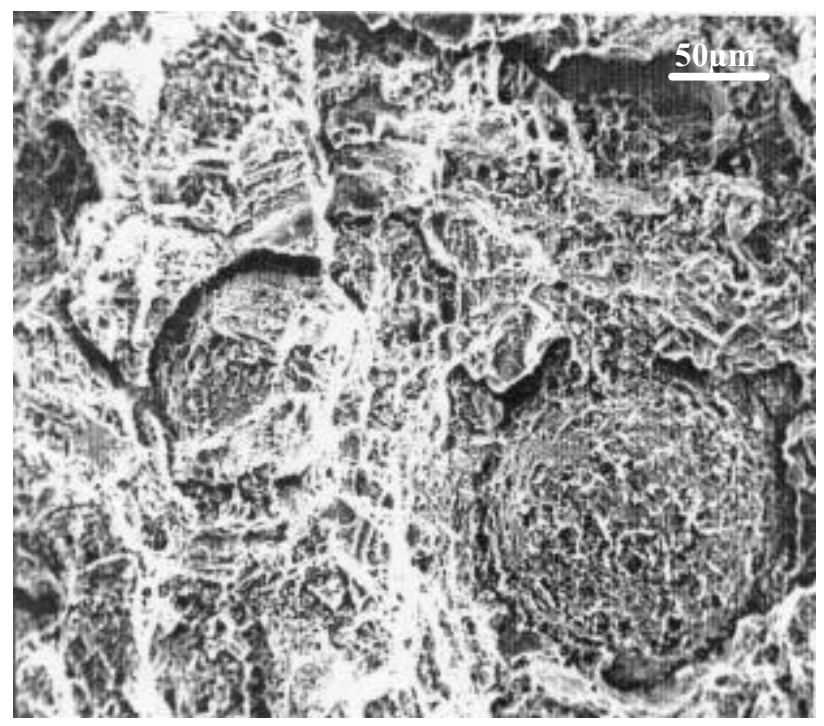

Figure 3. Fractograph of an as-received EP741NP specimen that shows the presence of PPB's.

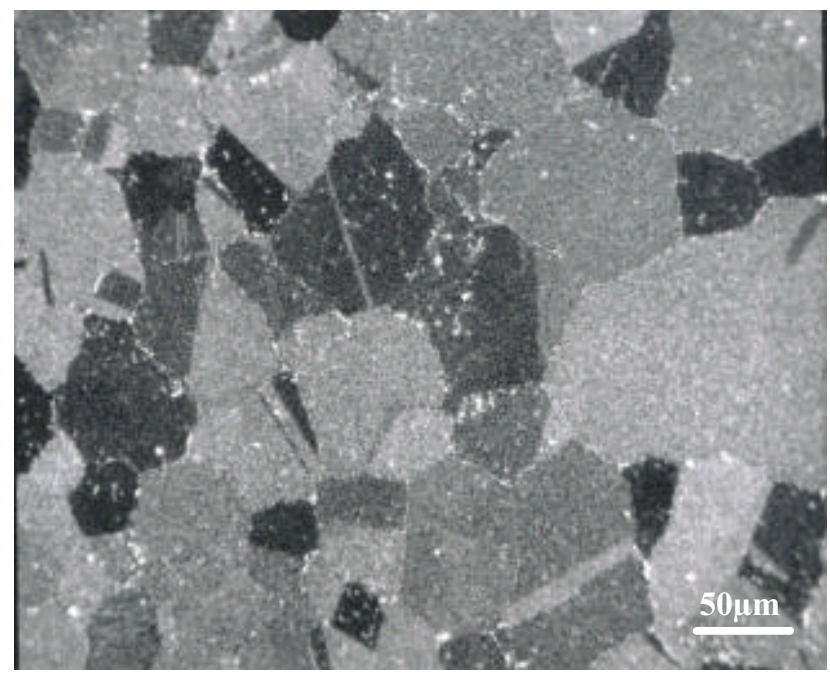

Figure 4. Typical grain structure of EP741NP processed with the standard, as-received heat treatment.

The grain boundaries showed extensive serrations and the presence of various precipitate phases. Figure 5 shows a typical grain boundary from the as-received material.

The gamma-prime within the as-received material was also characterized and was found to be very coarse (typically $0.5-0.8$ microns). The morphology of the gamma-prime was cuboidal, with some particles showing a near dendritic / four-fold pattern. Figure 6 shows the morphology of the gamma-prime in the as-received EP741NP material.

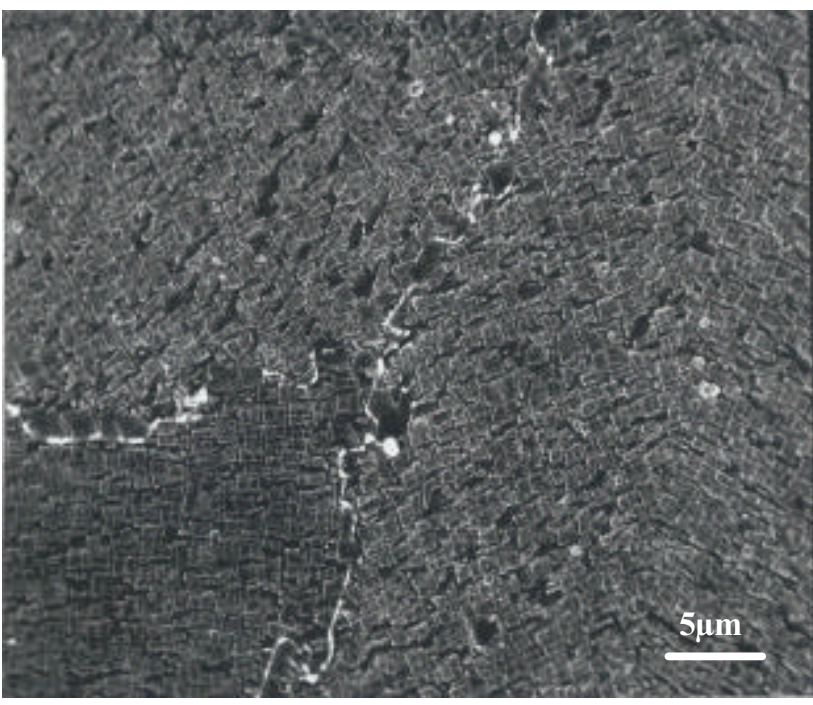

Figure 5. Photomicrograph of the serrated grain boundaries present the as-received EP741NP.

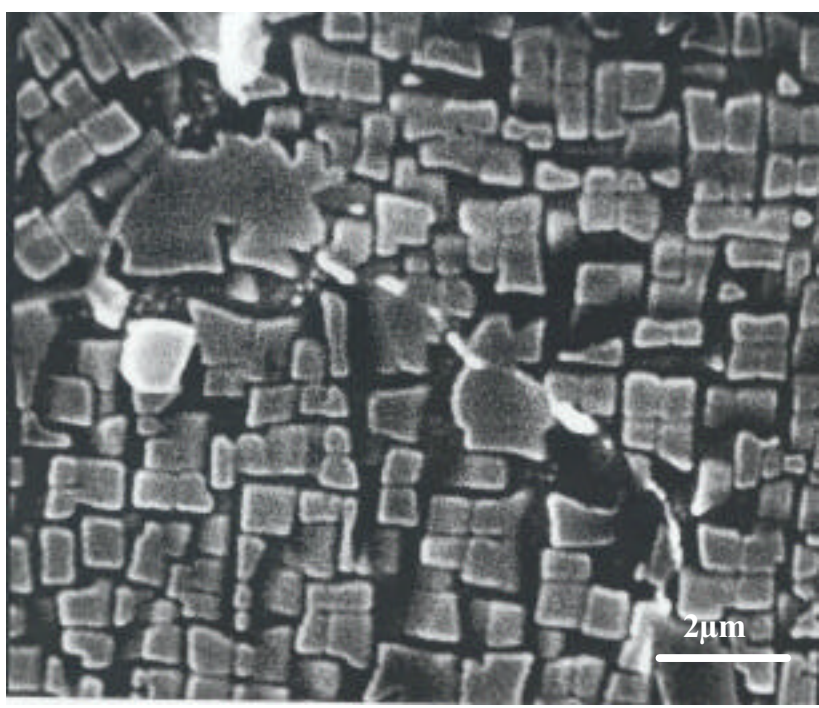

Figure 6. Photomicrograph showing the typical gammaprime size and distribution in the as-received EP741NP.

The structures in the heat treated samples were characterized to determine what if any changes occurred compared to the as-received material. The microstructure resulting from Heat Treatment-1 showed essentially a uniform spherical primary gamma-prime particle size of 0.15 microns. No large cuboidal or dendritic gammaprime was present in this material. The grain boundaries within this material were substantially straight as compared to the serrated grain boundaries seen in the asreceived material. Figure 7 shows the microstructure of the material given Heat Treatment-1. 


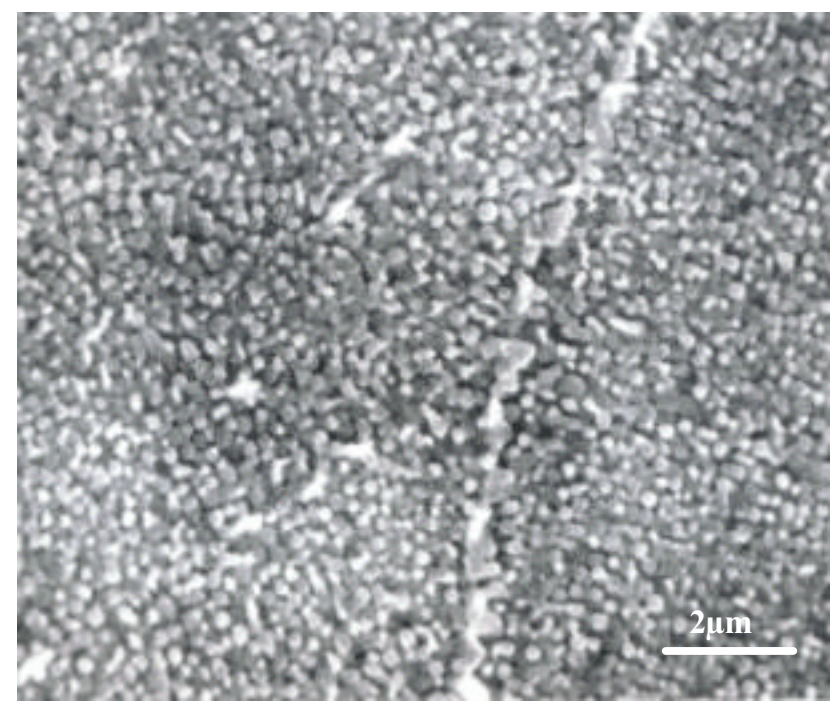

Figure 7. Photomicrograph of the EP741NP material after Heat Treatment-1.

The structures in the material given Heat Treatment-2 were found to be substantially different from those of the as-received and Heat Treatment-1 materials. The gammaprime phase in this heat treated material was found to be bimodal. Larger, 0.5-0.8 micron cuboidal and solid-state dendrites (up to 2 microns in size) were present. Substantial quantities of fine ( $=0.1$ micron) spherical gamma-prime particles were also observed. Figure 8 shows a typical photomicrograph of the structure in the sample given Heat Treatment-2.

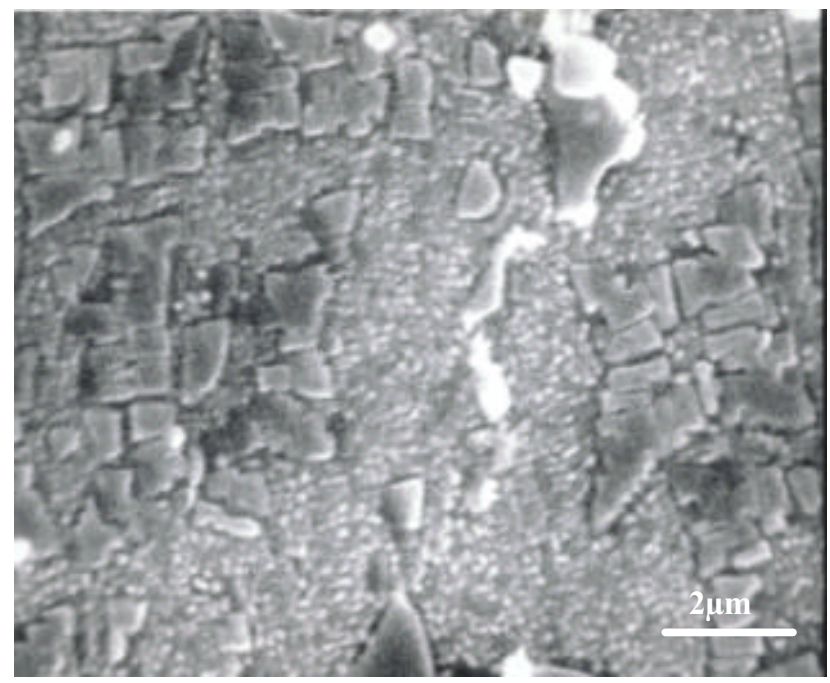

Figure 8. Photomicrograph of the typical gamma-prime structure observed in the EP741NP material given Heat Treatment-2.

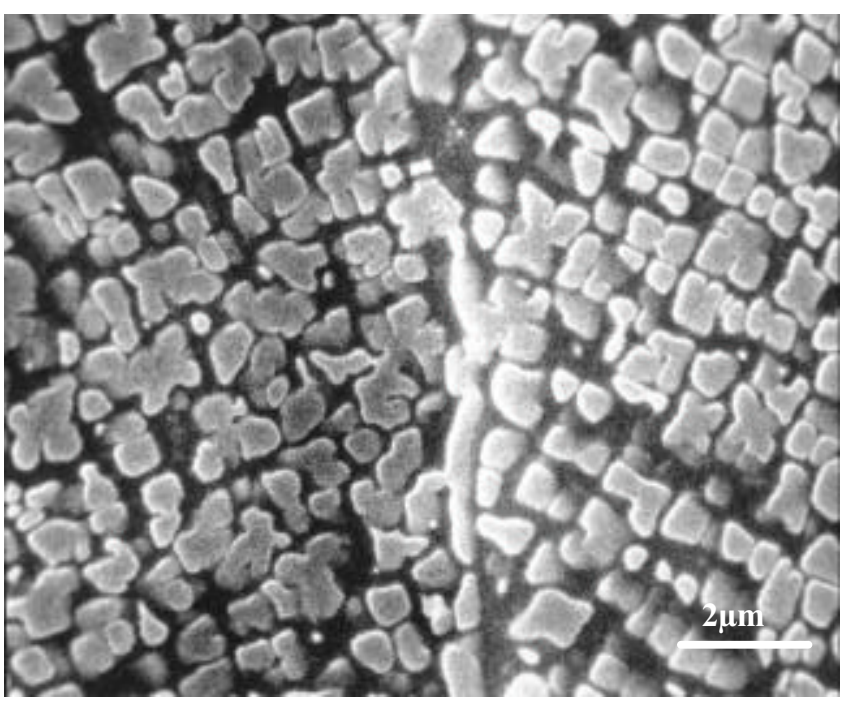

Figure 9. Photomicrograph of the EP741NP after Heat Treatment-3.

The sample which was given a slow furnace cool heat treatment, Heat Treatment-3, showed a structure that was closest to that of the as-received material. The gammaprime distribution and size closely matched the asreceived structure, with the exception of the large gammaprime were slightly smaller and have a much more rounded morphology as seen in Figure 9.

The sample that was given Heat Treatment- 6 resulted in the closest microstructure to that of the as-received sample material. This microstructure, as seen in Figure 10 , shows a large volume fraction of large, angular gamma-prime.

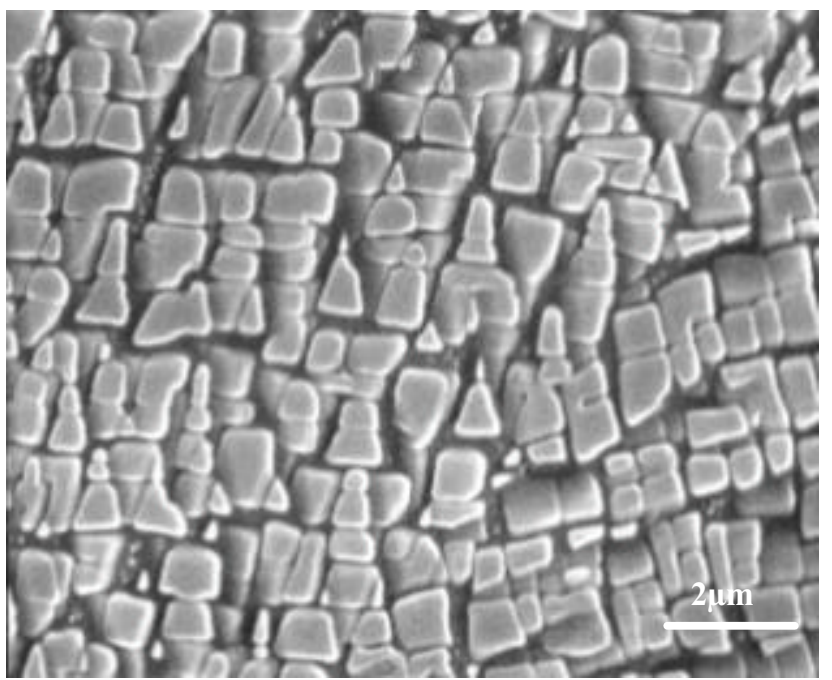

Figure 10. Photomicrograph of the typical gamma-prime structure observed in the EP741NP material given Heat Treatment-6. 


\section{$\underline{\text { X-Ray Diffraction and Phase Identification }}$}

The extraction residues from the as-received material were analyzed by SEM and X-ray diffraction analyses. The MC primary carbides phase was a $\mathrm{Nb}-\mathrm{Ti}$ rich $\mathrm{MC}$ with a lattice parameter of $4.42 \AA$. A small amount of $\mathrm{Hf}$ was found in the MC. Two minor phases were also present; an $\mathrm{M}_{6} \mathrm{C}$ and a $\mathrm{M}_{3} \mathrm{~B}_{2}$ phase. Both phases were rich in $\mathrm{Mo}, \mathrm{Cr}$, and $\mathrm{W}$.

Extractions and X-ray analyses were carried out on the heat treated samples and compared to residues from the as-received samples. The strongest $\mathrm{X}$-ray pattern was the MC phase, which had large amounts of $\mathrm{Nb}$ and $\mathrm{Ti}$ with smaller amounts of $\mathrm{Hf}$ present. Additional phases identified were $\mathrm{M}_{23} \mathrm{C}_{6}, \mathrm{M}_{6} \mathrm{C}$ and an $\mathrm{M}_{3} \mathrm{~B}_{2}$ boride. Figure 11 shows a typical XRD pattern resulting from material processed by Heat Treatment-1. The phases found are consistent with the alloy composition and the temperature of solution cycle and aging of the material.

\section{Mechanical Property Testing}

Tensile and creep testing was performed on the asreceived EP741NP material. The tabulated results of the mechanical property tests are listed in Table I.

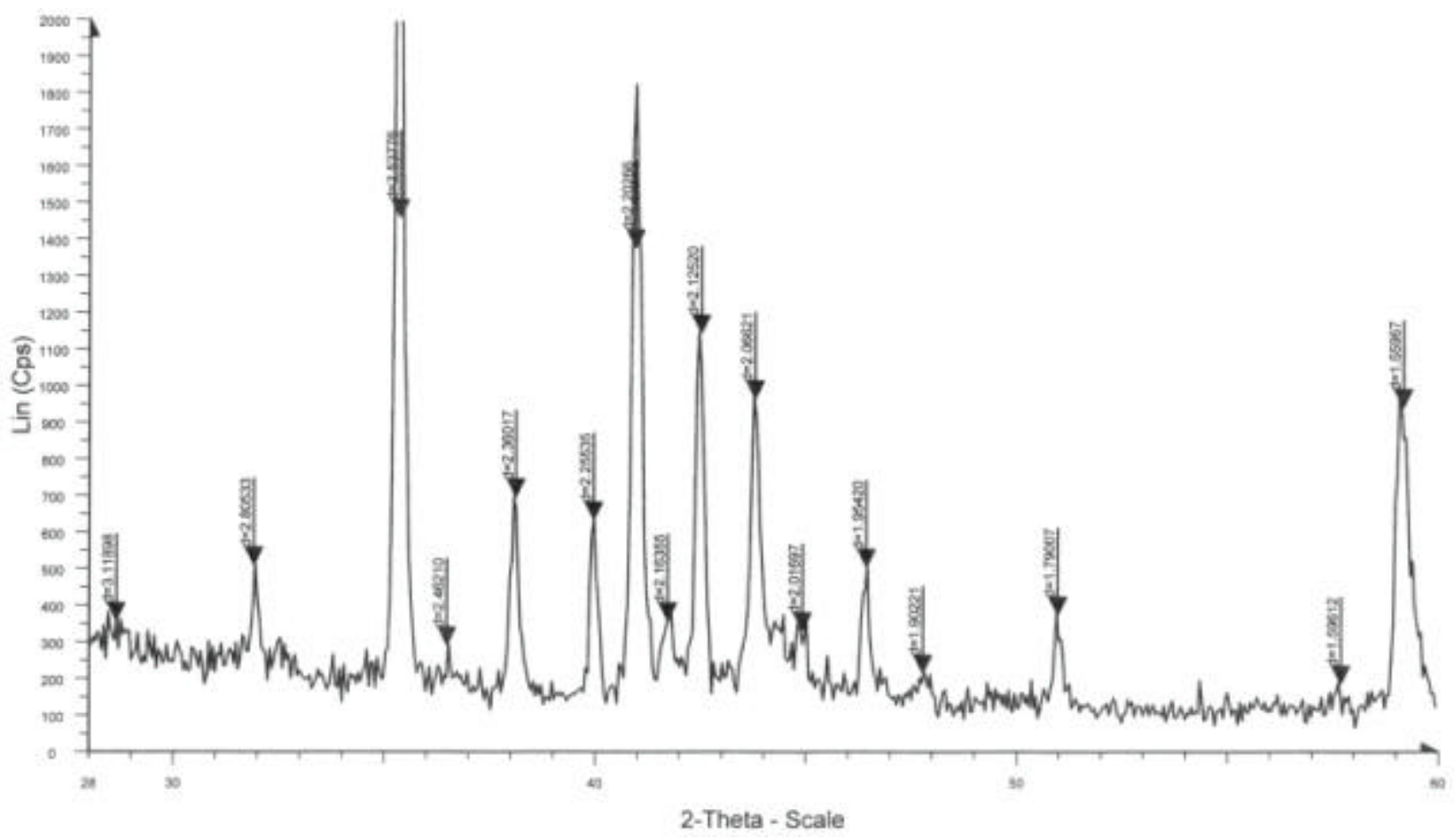

Figure 11. X-ray diffraction pattern from residue of the EP741NP processed by Heat Treatment-1

Table I. Mechanical property results from the as-received EP741NP material.

\begin{tabular}{|c|c|c|c|c|c|c|c|}
\hline ID & Test Type & $\begin{array}{c}\text { Test } \\
\text { Condition }\end{array}$ & $\begin{array}{c}\text { YS } \\
(\mathrm{MPa})\end{array}$ & $\begin{array}{c}\text { UTS } \\
(\mathrm{MPa})\end{array}$ & $\% \mathrm{E}$ & $\% \mathrm{RA}$ & $\begin{array}{c}\text { Hrs. to } \\
\text { Rupture }\end{array}$ \\
\hline 001 & Tensile & $538^{\circ} \mathrm{C}$ & 941 & 1313 & 17 & 22 & -- \\
\hline 002 & Tensile & $649^{\circ} \mathrm{C}$ & 976 & 1303 & 18 & 24.5 & -- \\
\hline 003 & Creep-Rupture & $649^{\circ} \mathrm{C} / 690 \mathrm{MP}$ & -- & -- & -- & -- & $*$ \\
\hline 004 & Creep-Rupture & $871^{\circ} \mathrm{C} / 207 \mathrm{MP}$ & -- & -- & -- & -- & 394.2 \\
\hline 005 & Creep-Rupture & $704^{\circ} \mathrm{C} / 690 \mathrm{MP}$ & -- & -- & -- & -- & 1090 \\
\hline
\end{tabular}

* sample exhibited $0.0 \%$ creep after 1500 hours, so sample was re-tested as sample 005 


\section{Microstructural Analysis of Mechanical Test Specimens}

The fractured ends of the tensile and creep-rupture bars were first examined on the SEM for the presence of PPB's. Each sample fracture showed large numbers of PPB's. A typical fractograph is shown in Figure 12.

Metallographic analyses were carried out only on the $704^{\circ} \mathrm{C}$ and $871{ }^{\circ} \mathrm{C}$ creep-rupture samples, since no structural changes are produced in tensile bars tested at $538^{\circ} \mathrm{C}$ and $649^{\circ} \mathrm{C}$.

The gamma-prime in the $704^{\circ} \mathrm{C}$ creep samples did not show any changes from the 1090 hour exposure. The gamma-prime edges are sharp and there was no evidence of matrix instability as shown in Figure 13.

A study of the grain boundaries shows that a Cr-rich phase $\left(\mathrm{Cr}_{23} \mathrm{C}_{6}\right)$ was beginning to form. This was evident by the presence of holes brought about by the Cr-rich particles being pitted out by electrolytic preparation-1. These holes can be seen in Figure 14. The amount of the Cr-rich phase was too low to detect in the extraction residues. The overall grain boundary precipitation is more clearly shown in Figure 15 when the test bars were prepared by electrolytic preparation-2.

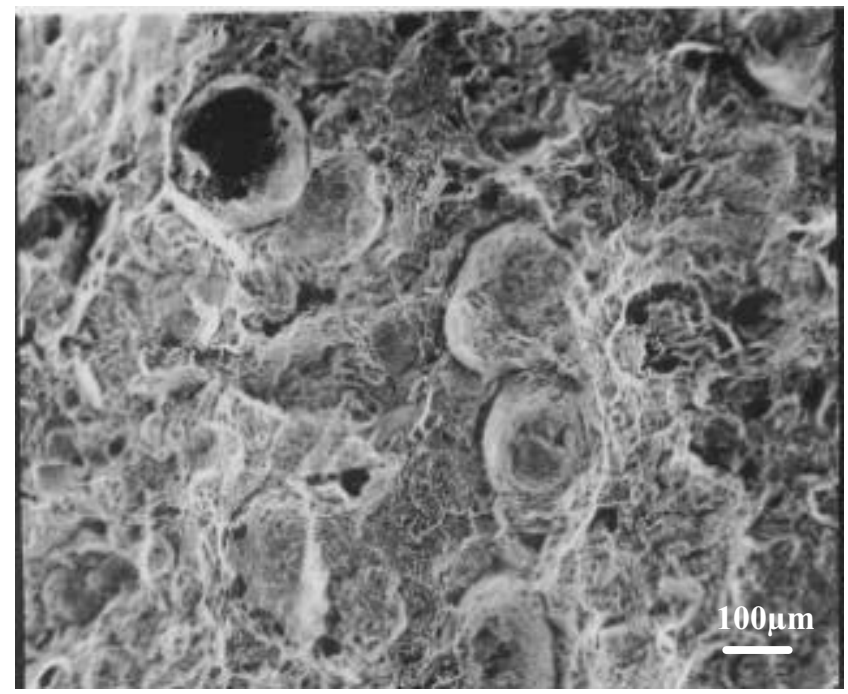

Figure 12. Fractograph of the EP741NP as-received material after $704^{\circ} \mathrm{C}$ creep-rupture testing.

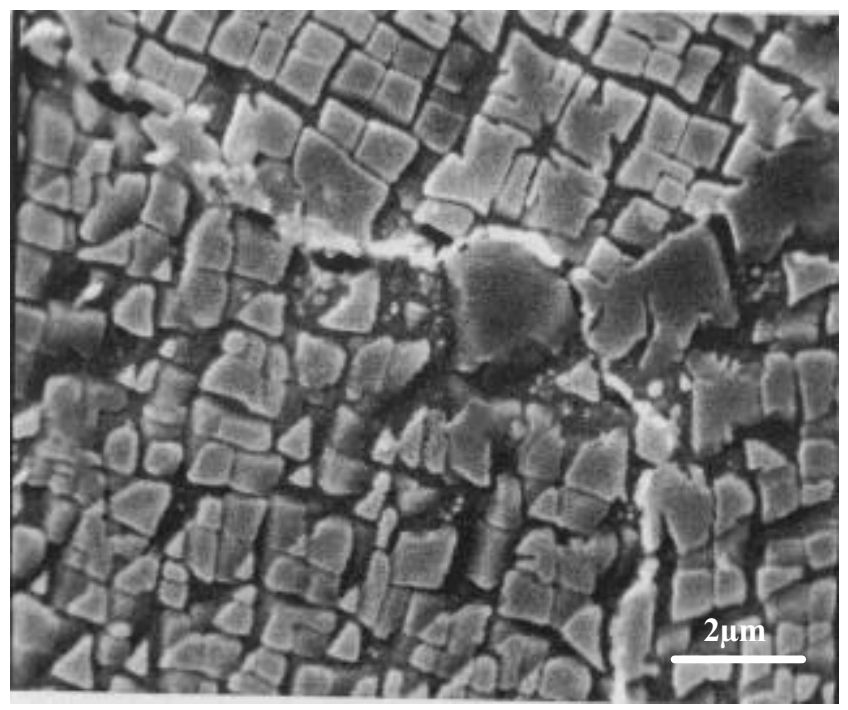

Figure 13. Photomicrograph of the gamma-prime in the $704^{\circ} \mathrm{C}$ creep-rupture sample.

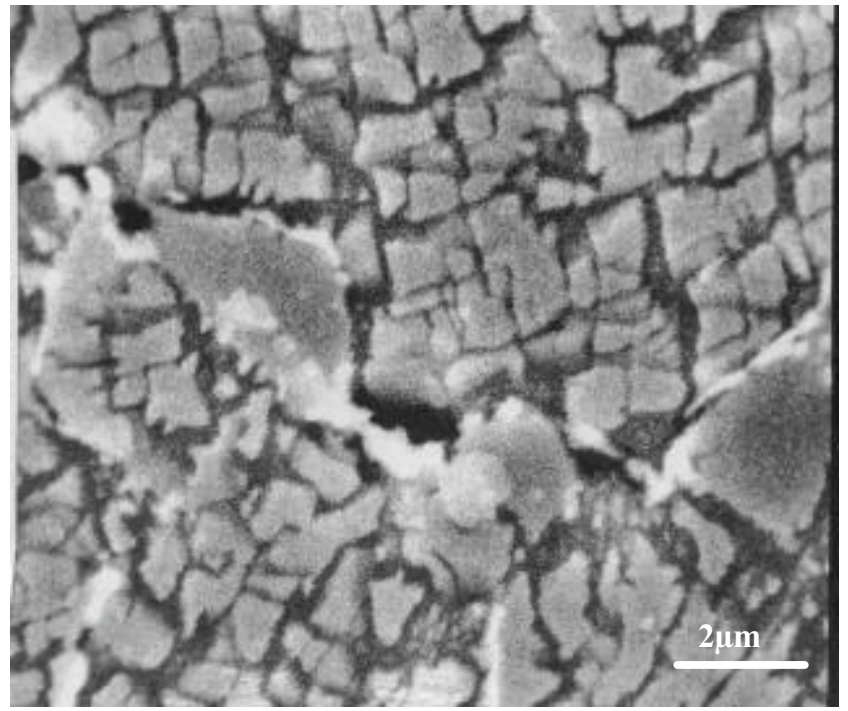

Figure 14. Photomicrograph of the grain boundaries and etch pits along the grain boundary in the $704^{\circ} \mathrm{C}$ creeprupture sample.

Creep-rupture testing for 394 hours at $871^{\circ} \mathrm{C}$ produced large structural changes as compared to the structures formed at $704^{\circ} \mathrm{C}$. The edges of the matrix gamma-prime have been rounded off, large gamma-prime agglomerations have occurred in the grain boundaries and in areas in the matrix (Figures 16 and 17). A large growth of what appears to be a carbide phase occurred in the grain boundaries and in the matrix areas where the gamma-prime agglomerations were present. The matrix was also seen to begin to show an instability as fine needles were starting to appear in the matrix (Figure 18). 


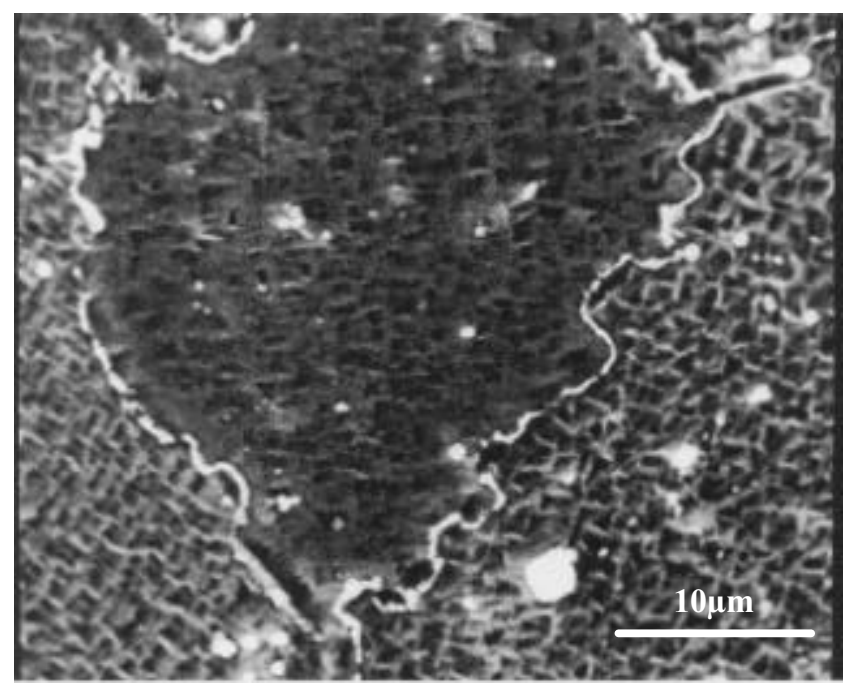

Figure 15. Photomicrograph of the grain boundary precipitate phase morphologies in the $704^{\circ} \mathrm{C}$ creep-rupture sample.

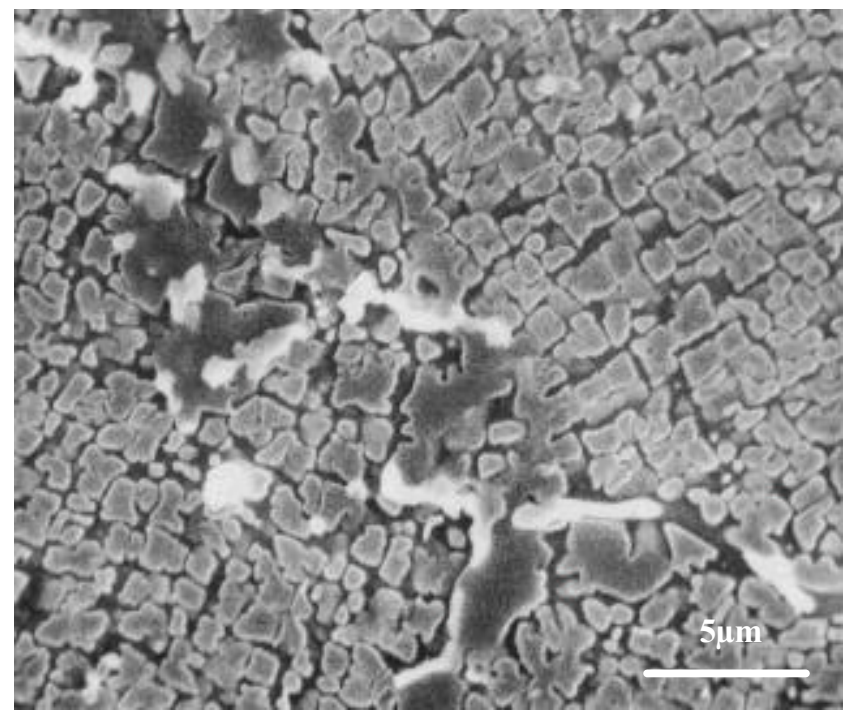

Figure 16. Photomicrograph of the grain boundary phases and morphologies in the $871^{\circ} \mathrm{C}$ creep-rupture sample.

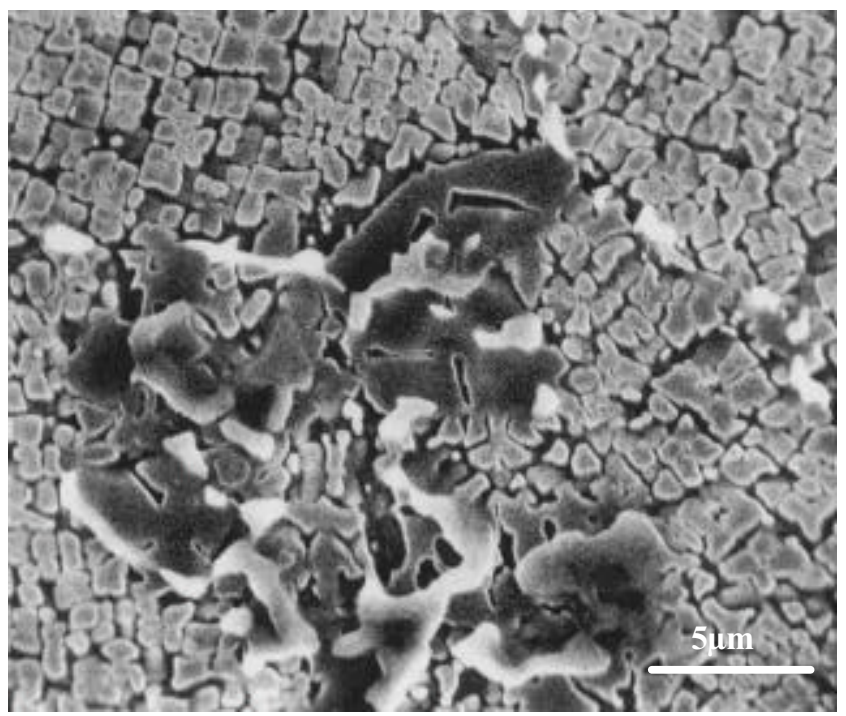

Figure 17. Photomicrograph of matrix gamma-prime agglomerations in the $871^{\circ} \mathrm{C}$ creep-rupture sample.

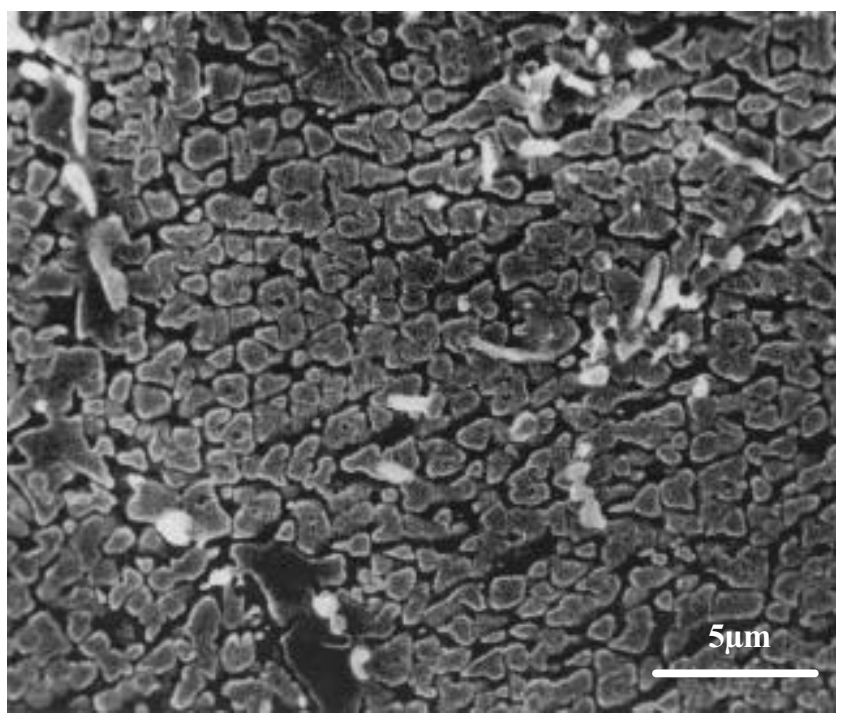

Figure 18. Photomicrograph of the needle phases that have formed during the $871^{\circ} \mathrm{C}$ creep-rupture test.

\section{Discussion}

EP741NP is an alloy that is seemingly of great interest and importance for the current and future generations of Russian military and commercial aircraft. There have been previously reported efforts on the characterization of this material from microstructural and mechanical property standpoints $[7,8,9,10]$. These previously reported results along with the current results indicate a large range in properties are possible. 
The aim of the chemistry for EP741NP is believed to be for an optimum balance of solid-solution strengthening for high temperature properties, while providing significant gamma-prime precipitate strengthening. The very large and sharp cuboidal gamma-prime precipitates observed in the as-received EP741NP indicates that the chemistries of the gamma-prime and gamma phases are such that there is a limited lattice mismatch, which could provide additional strength through the stability of the relatively large coherent gamma-prime.

The heat treatment that has been reported for this disc material is also interesting in that a very high temperature solution cycle is utilized to grow and set the grain size for this material. This very high temperature solution cycle may also provide some degree of primary carbide dissolution in an attempt to minimize the prior particle boundary decorations.

The standard heat treatment for EP741NP that was reportedly performed on the as-received material was designed to provide a balance of intermediate strength and greatly improved creep capabilities at elevated temperatures. It is also expected that the crack growth rate may be good for high temperature applications, as the strength properties were not maximized and the grain size was processed to a uniform coarse size.

The furnace cool from the high temperature solution is presumed to be selected to allow for large section sizes to be processed with reduced residual stresses and limited risk of quench cracking. The $1160^{\circ} \mathrm{C}$ temperature point appears to be slightly subsolvus, as evidence by the Heat Treatment-2 sample. It should be noted that the Heat Treatment-2 sample was furnace cooled to $1160^{\circ} \mathrm{C}$ and held at this temperature until the furnace stabilized and then the sample was removed and air cooled. It is conceivable that the as-received sample piece was furnace cooled to a furnace temperature of $1160^{\circ} \mathrm{C}$, while the mass of the potentially large disc cross-section would still be well above the gamma-prime solvus.

It is speculated that the as-received sample was actually a result of slow cooling through the gamma-prime precipitation and growth region. It if believed that the gamma-prime predominantly nucleated and grew to a relative coarse and uniform morphology during this step. The heat treatment utilized to produce the as-received material microstructure must have been sufficiently slow to allow coarsening and sharpening of the large gamma-prime precipitates. The disc heat treatment must have been slightly slower than that of the furnace cooling rate of Heat Treatment-3 over the range for the primary gamma-prime precipitation and growth. It is believed that the disc received either an intermediate temperature hold during the furnace cool from the solution heat treatment, similar to Heat Treatment-6, or the disc had a section size that was large enough to retard cooling during a non-interrupted furnace cool from the solution temperature.

Comparison of the tensile and creep properties measured from the as-received EP741NP material to those from the literature and for other materials are shown in Figures 19 and 20. The tensile strength is seen to be much lower then that of optimized U720, but comparable to that of AF115 and AF2-1DA6 processed in a similar manner.

The creep properties for the as-received EP741NP show them to be far superior to those of optimized U720, but again similar to that of AF115 and AF2-1DA6 processed in a similar manner. The prior particle boundaries proved to be very deleterious to this material during the very high temperature creep tests. The as-received EP741NP material showed gross fracture and crack growth along PPBs during the high temperature creep test as can be seen in Figure 12. 


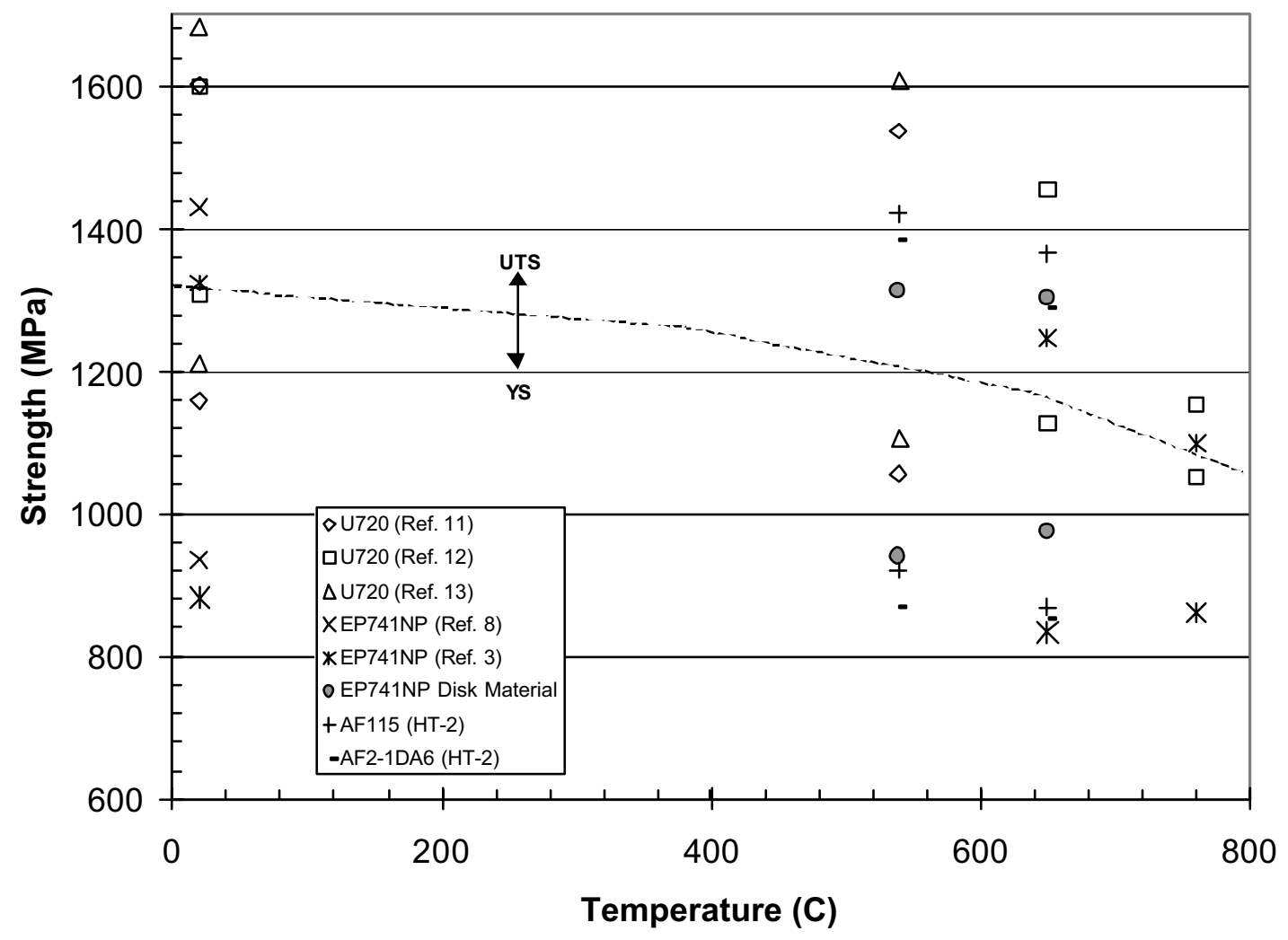

Figure 19. Tensile strength as a function of temperature for EP741NP compared with other nickel-base superalloys.

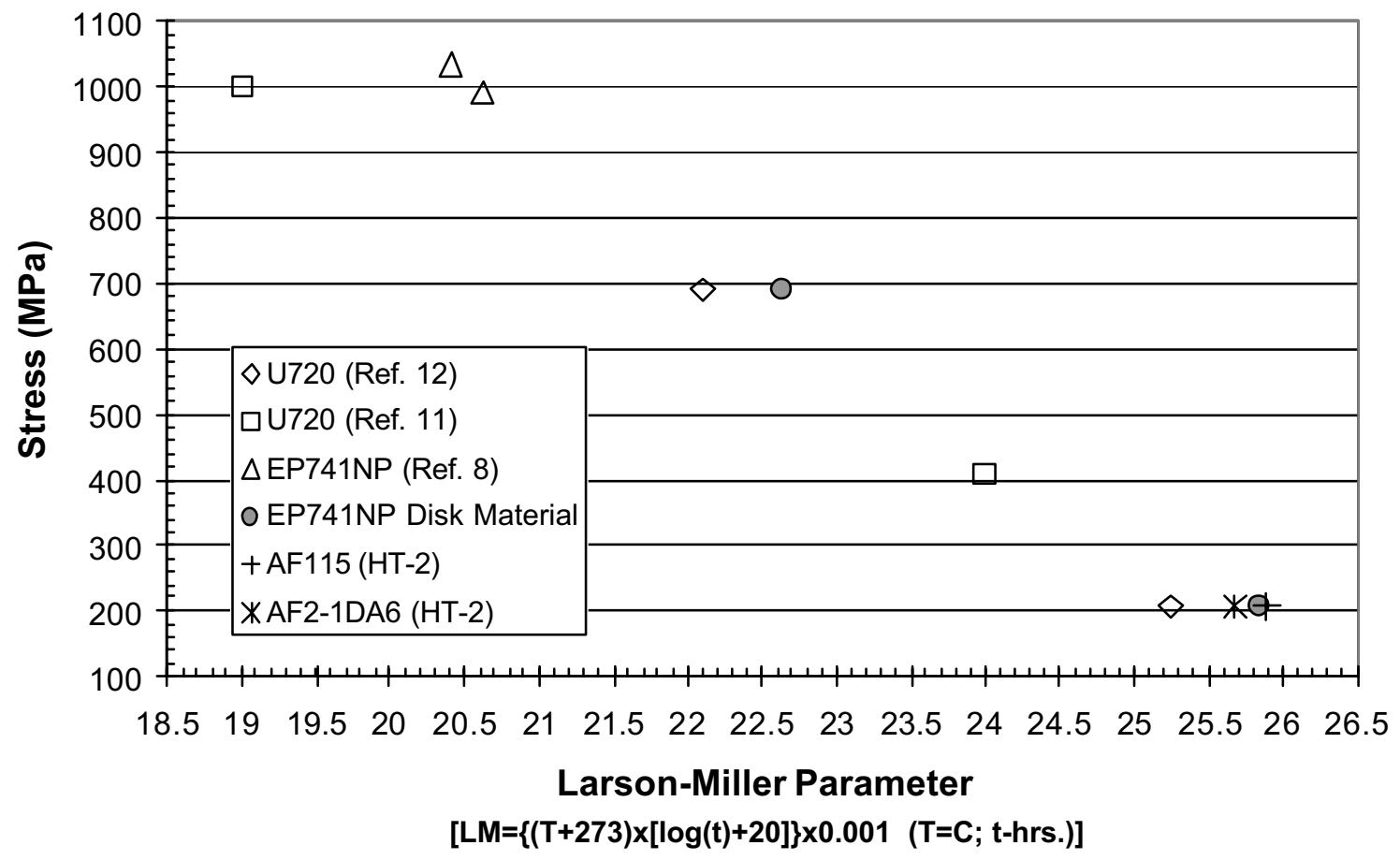

Figure 20. Creep-Rupture behavior for EP741NP and other nickel-base alloys. 


\section{$\underline{\text { Conclusions }}$}

- EP741NP material was characterized in this program

- The standard heat treatment for this alloy appears to be aimed at increased creep resistance and elevated temperature service rather than conventional lower temperature tensile strength.

- The standard heat treatment as utilized on the asreceived material has a high temperature solution cycle aimed at setting the grain size and partially dissolving the prior particle boundaries.

- Slow cooling is employed to allow large section sizes to be processed with reduced risk of quench cracking.

- A slow or interrupted cooling rate through the gammaprime precipitation and growth range was used to set the large gamma-prime size and distribution.

- The age cycle used for this material is believed to stabilize the gamma-prime and secondary carbide phases for optimum high temperature performance.

\section{Acknowledgements}

The authors would like to thank the Chinese Iron and Steel Research Institute (CISRI) for providing the sample material investigated. The authors would like to acknowledge Ladish Co., Inc. and Micro-Met Laboratories for support for this investigation. J. Radavich would like to thank Reference Metals for their support of this research program.

\section{$\underline{\text { References }}$}

1. "Powder Metallurgy Superalloy Lengthens Life of Jet Engines", Advanced Materials and Processes, September 2002, pp. 11-13.

2. G.S. Garibov and V.M. Chepkin, "Powder Metallurgy Superalloys Increase Service Life of AL31FP Engines for SU Fighters", Aeromat-2002, Orlando, FL, 2002.

3. Technical Report - Research and Production Amalgamation "All-Union Institute of Light Alloys" (VILS), "Superalloy EP741NP”.
4. N.F. Anoshkin, et. al., "The Development of Process for the Production of Finished Goods from Granulated Heat-Resistant Alloys with a Nickel base by High Temperature Isostatic Pressing", Metallurgical Science and the Treatment of Titanium and Heat Resistant Alloys, AILI, 1991, p. 313.

5. Prof. P. Yan, CISRI, Beijing China, Private Communications, 2001.

6. J.F. Radavich, "Microscopy of 718", JOM, vol. 41, July 1988, pp. 42-43.

7. L.S. Buslavsky, et. al., "Improvement of the Granulated Nickel Alloy EP741NP for the Purpose of an Increase in the Mechanical and Operating Characteristics", Technology of Light Alloys, Vol. 2, VILS, Russia, 1997, pp. 24-26.

8. J. Jackson and R. Rice, "Preliminary Material Properties Handbook", AFRL-ML-WP-TR-2001-4027, Battelle, July, 2000, pp. 6-33 - 6-36.

9. N.F. Anashkin, et. al., "Mechanical and Heat Resistant Properties of Alloy EP741NP Blanks Produced from Granules with a Coarseness of Less than 100 Microns" Metallurgical Science and the Treatment of Titanium and Heat Resistant Alloys, AILI, 1991, pp. 341.

10. N.Z. Pertsovskiy, et. al., "The Influence of Heat Treatment Procedures on the Precipitation of Secondary Carbides and Borides in Heat Resistant Nickel Alloy EP741NP", Metallurgical Science and the Treatment of Titanium and Heat Resistant Alloys, AILI, 1991, p. 323

11. D.U. Furrer and H.-J. Fecht, "Microstructure and Mechanical Property Development in Superalloy U720LI", Superalloys 2000, eds. T.M. Pollock, et. al., TMS, 2000, p. 415.

12. F.E. Sczerzenie and G.E. Maurer, "Development of Udimet 720 for High Strength Disk Applications", Superalloys 1984, eds., Gell, et. al., TMS, 1984, p. 573.

13. J.F Radavich and J. Hyzak, "Effect of Processing and Thermal Treatment on Alloy U720", Proceedings of the Tenth Int. Conf. on Vacuum Metallurgy, Beijing, China, June 11-15, 1990. 